\title{
LIXIVIAÇÃO DE NUTRIENTES DA SERAPILHEIRA RECÉM- DEPOSITADA EM SUCESSÃO ECOLÓGICA NA FLORESTA ATLÂNTICA, LITORAL DO PARANÁ
}

\author{
Kauana Melissa Cunha Dickow ${ }^{1}$, Renato Marques ${ }^{2}$, Carolina Benghi Pinto ${ }^{3}$ \\ ${ }^{1}$ Eng ${ }^{\text {a }}$. Florestal, M.Sc., Doutoranda em Engenharia Florestal, UFPR, Curitiba, PR, Brasil - kauanadickow@ yahoo.com.br \\ ${ }^{2}$ Eng. Florestal, Dr., Depto. de Solos e Engenharia Agrícola, UFPR, Curitiba, PR, Brasil - rmarques@ufpr.br \\ ${ }^{3}$ Eng $^{\mathrm{a}}$. Florestal, M.Sc., Curitiba, PR, Brasil - carolinabenghi@ vcs.com.br
}

Recebido para publicação: 06/08/2007 - Aceito para publicação: 10/03/2008

\begin{abstract}
Resumo
O presente estudo foi realizado na Floresta Ombrófila Densa das Terras Baixas, no litoral paranaense, onde foram instaladas parcelas em três fases sucessionais, denominadas fases sucessionais inicial, intermediária e avançada. Os objetivos do estudo foram avaliar a contribuição imediata das folhas de algumas espécies selecionadas e demais frações da serapilheira na liberação de nutrientes para o solo por meio da lixiviação. Para a coleta, foram instalados 10 coletores tipo cesta em cada fase sucessional. Esse material foi coletado durante um ano e lixiviado por pulverização em casa de vegetação, sendo analisada a concentração de $\mathrm{K}, \mathrm{Ca}, \mathrm{Mg}$ e $\mathrm{Na}$ no lixiviado coletado. Os resultados mostraram diferenças na liberação de nutrientes da serapilheira coletada ao longo das estações, ou seja, as condições climáticas apresentaram efeito sobre a qualidade da serapilheira lixiviada. O comportamento das fases sucessionais foi distinto, sendo que a maior liberação de nutrientes das folhas das espécies selecionadas ocorreu na fase avançada. A ordem decrescente de liberação de nutrientes da serapilheira foi a seguinte: $\mathrm{K}>\mathrm{Mg}>\mathrm{Na}>\mathrm{Ca}$. De forma geral, observou-se que os elementos foram liberados das frações da serapilheira na seguinte ordem decrescente: fração miscelânea > fração ramos e frutos > fração folhas.

Palavras-chave: Serapilheira; nutrição florestal; Floresta Ombrófila Densa.
\end{abstract}

\begin{abstract}
Leaching of nutrients in ecological succession in the Atlantic Florest in Parana state. The present study was carried out in the Floresta Ombrófila Densa on the low lands, in the State of Paraná. The plots were installed in three successional stages: initial, intermediary and advanced. The aim of this work was to evaluate the immediate contribution of leaf litter of selected tree species and other litter fractions on nutrient release to soil, through leaching. For litterfall collection, 10 collectors were installed per successional stage. Litterfall collected during one year, was leached by pulverization of deionized water and the concentration of $\mathrm{K}, \mathrm{Ca}, \mathrm{Mg}$ and $\mathrm{Na}$ analyzed. The results showed differences for nutrient released from litterfall in the course of the seasons, suggesting that climatic conditions affected the quality of the litter leached. The behavior of the successional stages was distinct and the highest nutrient release from the leaves occurred in the advanced stage. The highest nutrient release, in total litterfall, occurred in the initial stage. The sequence of nutrient release was the follow: $\mathrm{K}>\mathrm{Mg}$ $>\mathrm{Na}>\mathrm{Ca}$. Differences in the nutrient releasing from litter fractions were observed. The sequence was miscellaneous $>$ twigs and fruits $>$ leaves.

Keywords: Litterfall; forest nutrition; tropical forest.
\end{abstract}

\section{INTRODUÇÃO}

A denominada Floresta Ombrófila Densa das Terras Baixas consta entre as mais exuberantes florestas de clima tropical, sendo o litoral paranaense um dos últimos trechos da costa brasileira que ainda possui considerável extensão dessa formação vegetal. Apesar da sua importância na biodiversidade vegetal, a floresta tem sido intensamente submetida à ação antrópica, a qual provocou uma drástica redução de sua superfície original. 
A ciclagem de nutrientes em um ecossistema florestal é um dos processos mais importantes para a garantia da sua sustentabilidade. Essa ciclagem ocorre em particular através da decomposição da serapilheira, sendo uma das mais importantes fontes de nutrientes para a vegetação, principalmente onde os solos são arenosos e de baixa fertilidade, como é o caso do ecossistema estudado. Outra entrada significativa de nutrientes no solo mineral ocorre através da precipitação e da lixiviação da cobertura florestal e da serapilheira. Segundo Malavolta (1980), o lixiviado enriquece as camadas superiores do solo e tende a contrabalancear as perdas devidas à lixiviação nas camadas subsuperficiais do solo. $\mathrm{O}$ lixiviado das folhas afeta o número e o comportamento dos micro-organismos que, por sua vez, podem alterar a gênese do solo, sua textura e fertilidade. A lixiviação, desse modo, torna-se importante no desenvolvimento do processo de sucessão ecológica.

O conhecimento da dinâmica de funcionamento desse ecossistema deve contribuir de forma significativa com as bases necessárias para a proposição de ações que permitam uma correta restauração das áreas degradadas ou a conservação dos seus remanescentes. Nesse sentido, o objetivo deste trabalho foi avaliar a contribuição da lixiviação das frações de serapilheira (folhas de spp. selecionadas e demais frações) antes de sua decomposição no solo.

\section{MATERIAL E MÉTODOS}

\section{Área de estudo}

A área estudada faz parte da Floresta Estadual do Palmito, localizada no município de Paranaguá (PR), entre as coordenadas $25^{\circ} 35^{\prime}$ de latitude sul e $48^{\circ} 32^{\prime}$ de longitude oeste.

O clima predominante é o Cfa, segundo Köppen, caracterizado como subtropical úmido, com temperatura média do mês mais quente superior a $22{ }^{\circ} \mathrm{C}$ e do mês mais frio entre -3 e $18{ }^{\circ} \mathrm{C}$, com precipitação do mês mais seco superior a $60 \mathrm{~mm}$ (IAPAR, 1978). A área está situada em uma classe de solo denominada Espodossolo, com diferenças na espessura e profundidade de ocorrência dos horizontes, assim como no grau de consistência do horizonte espódico. A análise granulométrica indica um solo arenoso, com teores de areia variando entre 90 e $98 \%$, dependendo do horizonte considerado. O solo apresenta-se ácido em todo o perfil, com valores de $\mathrm{pH}$ da ordem de 3,2 para o horizonte A e 3,9 para o horizonte E. A saturação por bases varia entre 8 e $16 \%$ no horizonte A. Os teores de carbono são da ordem de $60 \mathrm{~g} . \mathrm{dm}^{-3}$ nas fases sucessionais inicial e avançada e da ordem de $110 \mathrm{~g}^{-\mathrm{dm}^{-3}}$ na fase sucessional intermediária (WISNIEWSKI et al., 1997).

A vegetação original da área de estudo era a Floresta Ombrófila Densa das Terras Baixas, que foi intensamente explorada no passado para a extração de madeira e palmito, sendo, em algumas áreas, desmatada para o uso do solo em atividades agrícolas de subsistência. Devido às limitações produtivas do solo, essas áreas eram utilizadas por períodos relativamente curtos e abandonadas, permitindo que uma sucessão secundária se desenvolvesse. Para esse estudo, selecionaram-se três áreas em diferentes fases sucessionais, as quais foram denominadas de fase sucessional inicial, intermediária e avançada.

A fase sucessional inicial é caracterizada por uma vegetação baixa, esparsa e pouco diversificada, com 4 metros de altura média. As árvores, bem espaçadas entre si $\left(\mathrm{G}=5,3 \mathrm{~m}^{2}\right.$.ha ${ }^{-1}$; PAP $\geq$ $10 \mathrm{~cm}$ ), formam touças oriundas de rebrotas, e seus troncos têm diâmetros pequenos, em torno de $5 \mathrm{~cm}$ em média. A fisionomia é homogênea - poucas são as plantas epífitas e raras as bromélias. O solo é, em grande extensão, coberto por liquens fruticulosos, e dentre as espécies arbóreas destaca-se a caúna (Ilex theezans Mart.), compreendendo 77,5\% das árvores.

$\mathrm{Na}$ fase sucessional intermediária, podem ser encontrados dois estratos distintos e um terceiro começando a se diferenciar. Não há clareiras na vegetação e a floresta é sombreada e úmida $(\mathrm{G}=34,7$ $\mathrm{m}^{2}$.ha ${ }^{-1}$, PAP $\geq 10 \mathrm{~cm}$ ). As árvores mais altas atingem $12,5 \mathrm{~m}$ de altura média, enquanto o segundo estrato encontra-se em torno de $8 \mathrm{~m}$. O sub-bosque está repleto de bromélias, aparecendo também epífitas das famílias Orquidaceae e Araceae, além de cactos pendentes (Rhipsalis spp. Gaertn.), herbáceas terrestres de Liliaceae e Iridaceae, arbustos de Rubiaceae e Melastomataceae e trepadeiras da família Sapindaceae, entre outras.

$\mathrm{Na}$ fase sucessional avançada, podem ser observados três estratos distintos e sub-bosque rico em Bromeliaceae, Araceae e Polipodiaceae (entre outras, lianas e trepadeiras). As guaminhovas (Geonoma spp. Willd.) são abundantes e caracterizam, em grande parte, o estrato inferior, distribuindo-se por entre as herbáceas e arbustivas. O estrato superior possui entre 11 e $14 \mathrm{~m}$ de altura e é caracterizado 
principalmente pela ocorrência da Tapirira guianensis Aubl. (cupiúva), Calophyllum brasiliensis Cambess. (guanandi), Myrcia racemosa Barb. Rodr. (guapiranga), Ocotea aciphylla (Nees) Mez. (canelaponta-de-lança), Euterpe edulis Mart. (palmito) e Ocotea pulchella Mart. (canela-lageana). A área basal total $(\mathrm{G})$ é de $37,3 \mathrm{~m}^{2} / \mathrm{ha}(\mathrm{PAP} \geq 10 \mathrm{~cm})$. Essa variedade de espécies indica que a restinga passou a ser Floresta Ombrófila Densa das Terras Baixas novamente (WISNIEWSKI et al., 1997).

\section{Coleta da serapilheira}

A serapilheira foi coletada em coletores de tela de nylon (malha $2 \mathrm{~mm}$ ) montada em estrutura quadrada de tubo de PVC, com $56 \mathrm{~cm}$ de lado, distantes a $70 \mathrm{~cm}$ do solo. Esses coletores foram instalados em três áreas experimentais de $1000 \mathrm{~m}^{2}$ cada, as quais correspondem às fases sucessionais inicial, intermediária e avançada. Foram distribuídos aleatoriamente 10 coletores por área, totalizando 30 pontos de coleta. As coletas foram realizadas a cada três semanas, durante um ano (abril de 1998 a abril de 1999).

No laboratório, a serapilheira foi acondicionada em sacos de papel, pré-secada e separada nas seguintes frações: fração folhas (F), fração ramos, flores e frutos (RFF) e fração miscelânea (todo material restante, não identificável) (M). Da fração $\mathrm{F}$ foram selecionadas as folhas de algumas espécies para estudo específico da contribuição delas na ciclagem de nutrientes. A seleção das espécies baseou-se em dois critérios: espécies com maior Valor de Importância (VI) (estudo realizado por WISNIEWSKI et al., 1997) e sua ocorrência nos coletores durante o período de coleta. A relação das espécies selecionadas nas três fases sucessionais é apresentada na tabela 1.

Tabela 1. Espécies selecionadas nas fases sucessionais inicial, intermediária e avançada e seus respectivos valores de importância.

Table 1. Selected species in the initial, intermediary and advanced secondary successional stages and their respective importance values.

\begin{tabular}{llc}
\hline Fase Sucessional & \multicolumn{1}{c}{ Espécie } & VI (\%)* \\
\hline Inicial & Ilex theezans Mart. (caúna) & 159,6 \\
& Ternstroemia brasiliensis Cambess. (vermelho) & 29,2 \\
& Ocotea pulchella Mart. (canela-lageana) & 16,5 \\
& Pera glabrata (Schott) Poepp. ex Baill. (tabocuva) & 15,5 \\
Intermediária & Ilex theezans Mart. (caúna) & 72,9 \\
& Ternstroemia brasiliensis Cambess. (vermelho) & 31,6 \\
& Rapanea venosa (A. DC.) Mez (capororocão) & 30,0 \\
& Gomidesia schaueriana O. Berg (rapagoela) & 29,6 \\
& Clusia criuva Cambess. (mangue-do-mato) & 14,4 \\
Avançada & Ocotea pulchella Mart. (canela-lageana) & 13,2 \\
& Tapirira guianensis Aubl. (cupiúva) & 29,1 \\
& Ocotea aciphylla (Nees) Mez (canela-ponta-de-lança) & 20,5 \\
& Ocotea pulchella Mart. (canela-lageana) & 16,6 \\
& Myrcia racemosa Barb. Rodr. (guapiranga) & 12,5 \\
\hline
\end{tabular}

*VI $($ Valor de Importância) $=$ DR (densidade relativa) + FR (frequência relativa) + DoR (dominância relativa)

Depois de separada nas suas diferentes frações, a serapilheira foi secada em estufa $\left(65 \pm 5{ }^{\circ} \mathrm{C}\right) \mathrm{e}$ pesada para obtenção do valor da fitomassa seca. A serapilheira coletada durante todo o período foi agrupada, a cada quatro coletas, para estimativa do peso de fitomassa seca produzida e quantidade de nutrientes lixiviados da serapilheira em cada estação do ano.

\section{Ensaio de lixiviação}

Para o ensaio de lixiviação da serapilheira, foram compostas três repetições de cada fração e subfração (espécies selecionadas) por fase sucessional, sendo que o peso das amostras foi calculado em função da representatividade, ou seja, da porcentagem de ocorrência das folhas, ramos, galhos, etc. na serapilheira total coletada na estação. Foram realizados quatro ensaios de lixiviação da serapilheira, cada um correspondendo a uma estação do ano. 
As amostras foram acomodadas em funis acoplados em recipientes de polietileno para a coleta da solução lixiviada. O ensaio foi realizado através de simulação de chuva, utilizando-se um pulverizador contendo água deionizada. A pulverização foi conduzida durante aproximadamente 8 minutos, e o volume de água utilizado foi de $15 \mathrm{~mm}$ em média. A quantidade de solução coletada foi medida em cada um dos recipientes utilizados. Em seguida, as soluções foram filtradas (filtro de $0,45 \mu \mathrm{m}$ ) para a realização das análises químicas.

\section{Análises químicas}

As análises químicas foram realizadas no laboratório de Biogeoquímica e Nutrição de Plantas do Departamento de Solos e Engenharia Agrícola da UFPR. Os elementos foram determinados diretamente na solução de lixiviação: $\mathrm{K}$ e $\mathrm{Na}$ foram determinados por emissão atômica e $\mathrm{Ca}$ e $\mathrm{Mg}$ por absorção atômica em espectrofotômetro Perkin-Elmer 2380.

\section{Cálculo das quantidades lixiviadas e porcentagem de lixiviação}

A quantidade de cada elemento no lixiviado ("quantidade estimada no lixiviado"), referente ao peso de material submetido ao ensaio, foi calculada da seguinte forma:

Quantidade estimada do elemento no lixiviado $\left(\mathrm{mg}_{\mathrm{kg}} \mathrm{k}^{-1}\right.$ ou $\left.\mathrm{g}-\mathrm{kg}^{-1}\right)=$ [teor do elemento no lixiviado $\left(\mathrm{mg} \cdot \mathrm{L}^{-1}\right) \mathrm{x}$ volume lixiviado $\left.(\mathrm{mL})\right] /$ peso seco do material vegetal submetido à lixiviação $(\mathrm{g})$ (Figuras 1 a 4). Esses dados de lixiviação são referentes à chuva simulada de $15 \mathrm{~mm}$ em casa de vegetação.

A quantidade estimada de cada elemento no lixiviado (do ensaio de simulação de chuva de 15 $\mathrm{mm}$ ) foi multiplicada pela quantidade de serapilheira produzida no período. Esse cálculo foi realizado para se obter a "quantidade relativa no lixiviado", ou seja, a quantidade que seria liberada de cada elemento se toda a serapilheira produzida $\left(\mathrm{kg} \cdot \mathrm{ha}^{-1}\right)$ no período do estudo (abril de 1998 a abril de 1999) fosse submetida a uma precipitação de, no mínimo, $15 \mathrm{~mm}$.

A porcentagem de lixiviação foi calculada com base na quantidade do elemento depositado via serapilheira (as quantidades depositadas dos elementos foram obtidas do trabalho de Pinto e Marques, 2003) e na quantidade relativa do elemento no lixiviado da serapilheira. O cálculo utilizado foi o seguinte:

$\%$ lixiviação $=$ [quantidade relativa do elemento no lixiviado $\left(\mathrm{kg} \cdot \mathrm{ha}^{-1} \cdot \mathrm{ano}^{-1}\right) /$ quantidade depositada do elemento $\left.\left(\mathrm{kg} \cdot \mathrm{ha}^{-1} \cdot \mathrm{ano}^{-1}\right)\right]$ x 100 (Tabela 3).

\section{Análise estatística}

A análise estatística dos dados foi realizada com o software STATGRAPHICS Plus 4.1. A homogeneidade das variâncias foi verificada com o teste de Bartlett, sendo que alguns dados tiveram que ser transformados (raiz quadrada e log (10)) para possibilitar o teste. Após a transformação dos dados, realizou-se a análise de variância (ANOVA), e as médias foram comparadas pelo teste de Fischer's LSD a $5 \%$ de probabilidade.

\section{RESULTADOS E DISCUSSÃO}

De forma geral, observou-se que os elementos foram liberados da serapilheira na seguinte ordem: M > RFF e F (Figuras 1, 2, 3 e 4). A fração M está formada por um material mais fragmentado e decomposto em relação às outras frações, o que aumenta a área de contato da água com o material e facilita a extração de elementos minerais.

Outra tendência observada para os quatro elementos estudados ao longo do ano, em termos de serapilheira total, foi a maior contribuição da fase inicial de sucessão na liberação de nutrientes para o solo. Isso indica uma estratégia das espécies da fase pioneira no preparo das condições ambientais para instalação das espécies subsequentes. Segundo Gómez-Pompa e Vásquez-Yanes (1981), as espécies pioneiras também melhoram as condições pedológicas, através da produção de larga quantidade de matéria orgânica, facilitando o estabelecimento de espécies sucessionais tardias.

Com os resultados encontrados neste trabalho, procurou-se demonstrar a importância da lixiviação dentro do processo de decomposição do material vegetal. Entretanto, é importante lembrar que a lixiviação engloba tanto os compostos solúveis provenientes do próprio material em decomposição 
quanto os de deposição de aerossóis. Diferentemente do que ocorre na floresta, onde a água da chuva (já enriquecida pela lavagem da atmosfera) interage com os tecidos vegetais vivos e mortos (serapilheira), neste trabalho foi avaliada a interação da água deionizada com os tecidos vegetais antes da sua decomposição efetiva no solo, para se quantificar a contribuição das diferentes frações da serapilheira e de diferentes espécies florestais na ciclagem de nutrientes. A seguir é feita uma discussão do comportamento individual dos elementos minerais.

\section{Quantidade estimada de K, Ca, Mg e Na no lixiviado}

Potássio

O potássio, comparado aos outros elementos analisados, foi o que apresentou as maiores quantidades estimadas no lixiviado da serapilheira (Figuras 1, 2, 3 e 4). Esse resultado já era esperado, uma vez que o $\mathrm{K}$ é um elemento altamente solúvel $\mathrm{e}$, por isso, facilmente lixiviável tanto de órgãos vegetais vivos quanto mortos (MENGEL e KIRKBY, 1982; SPURR e BARNES, 1980; MALAVOLTA, 1980; JONES JUNIOR, 1998). Esse comportamento é corroborado pelos resultados observados por Britez (1994) e Souza (2006) em ambiente de Floresta Ombrófila Densa das Terras Baixas no litoral do estado do Paraná. Esses autores observaram que, após a interação da água da chuva com a vegetação, o K apresentou concentrações bem maiores na água que atravessou o dossel da floresta. Marques e Ranger (1997), em estudo realizado em povoamento de Pseudotsuga menziesii, observaram que a principal fonte de $\mathrm{K}$ do lixiviado do dossel foi a interação da água da chuva com as partes internas do tecido foliar. Segundo Britez (1994), o K que atravessa o dossel da floresta é proveniente da lavagem da deposição seca e da solubilização desse elemento das folhas. No caso da serapilheira, esse mesmo comportamento é observado, sendo as quantidades de $\mathrm{K}$ encontradas no lixiviado da serapilheira provenientes de deposição seca e do próprio tecido vegetal.
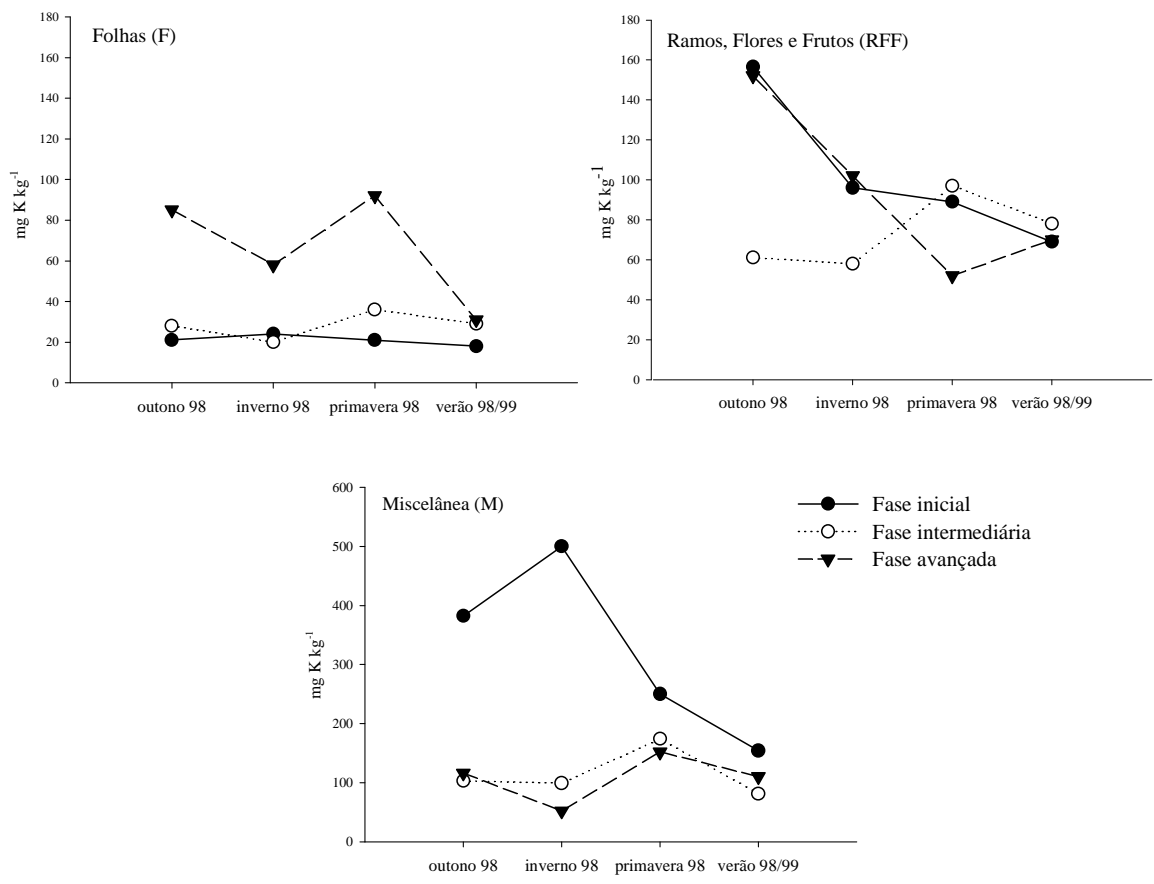

Figura 1. Quantidade estimada de $\mathrm{K}\left(\mathrm{mg} \cdot \mathrm{kg}^{-1}\right)$ no lixiviado das frações $F$, RFF e $M$ nas fases sucessionais inicial, intermediária e avançada, ao longo das estações do ano.

Figure 1. Estimated amount of $\mathrm{K}\left(\mathrm{mg} \cdot \mathrm{kg}^{-1}\right)$ leached from the F, RFF and $\mathrm{M}$ fractions in the initial, intermediary and advanced secondary successional stages, along the seasons of the year.

A lixiviação de $\mathrm{K}$ da fração $\mathrm{F}$ variou pouco ao longo das estações do ano, nas fases inicial e intermediária. Já na fase avançada, a variação foi maior, sendo que as maiores quantidades ocorreram na lixiviação do material coletado no outono e na primavera. 
O comportamento da lixiviação de $\mathrm{K}$ da fração RFF foi bem distinto da fração F. Nas fases inicial e avançada, observou-se uma elevada lixiviação no outono, a qual diminuiu consideravelmente ao longo das demais estações do ano. Na fase intermediária, a variação foi menor, porém a maior lixiviação ocorreu na primavera.

Para a fração $\mathrm{M}$ da fase inicial, a maior lixiviação ocorreu no inverno. Na fase intermediária, a variação ao longo do ano foi pequena, porém a lixiviação foi um pouco superior na primavera. Na fase avançada, o outono e a primavera apresentaram praticamente os mesmos valores de lixiviação de $\mathrm{K}$.

As quantidades estimadas de $\mathrm{K}$ no lixiviado da fração $\mathrm{M}$ foram muito superiores às demais frações. O material dessa fração encontrava-se bastante fragmentado, propiciando maior área de contato com a água e, portanto, potencializando a extração de elementos minerais.

As médias das quantidades estimadas de $\mathrm{K}$ no lixiviado (considerando todas as frações da serapilheira e fases sucessionais) foram de $123,112,107$ e $71 \mathrm{mg} \cdot \mathrm{kg}^{-1}$ no outono, inverno, primavera e verão, respectivamente. É interessante observar que a maior média ocorreu no outono e diminuiu em direção ao verão. Por outro lado, a precipitação média foi de 145, 335, 599 e $1.554 \mathrm{~mm}$ no outono, inverno, primavera e verão, respectivamente. Portanto, as maiores lixiviações ocorreram nas estações em que a precipitação média foi menor, ou seja, a serapilheira que ficou nos coletores entre os períodos de coleta sofreu menor interação com a precipitação, e quando esse material foi novamente lixiviado com água deionizada em casa de vegetação, os teores extraídos foram maiores. O oposto também é verdadeiro, ou seja, a serapilheira coletada nos períodos de maior precipitação (primavera e verão) apresentou as menores quantidades estimadas de $\mathrm{K}$ no lixiviado devido à constante lavagem do material nesse período.

Cálcio

Para as três frações e fases sucessionais, o comportamento da lixiviação do Ca foi semelhante, ou seja, as quantidades aumentaram bastante do outono para o inverno, apresentaram uma queda acentuada na primavera e voltaram a aumentar um pouco no verão (Figura 2).
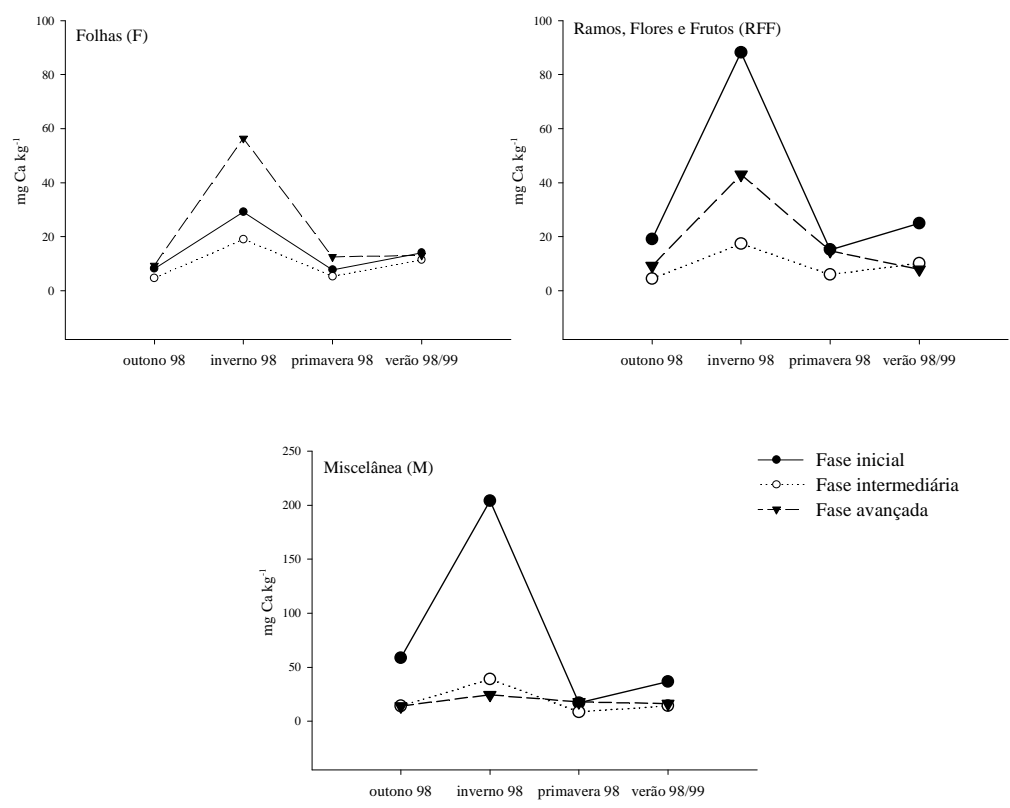

Figura 2. Quantidade estimada de $\mathrm{Ca}\left(\mathrm{mg}^{\mathrm{kg}} \mathrm{kg}^{-1}\right)$ no lixiviado das frações $\mathrm{F}$, RFF e $\mathrm{M}$ nas fases sucessionais inicial, intermediária e avançada, ao longo das estações do ano.

Figure 2. Estimated amount of $\mathrm{Ca}\left(\mathrm{mg}^{\mathrm{kg}} \mathrm{kg}^{-1}\right)$ leached from the $\mathrm{F}, \mathrm{RFF}$ and $\mathrm{M}$ fractions in the initial, intermediary and advanced secondary successional stages, along the seasons of the year.

$\mathrm{Na}$ fração $\mathrm{F}$, a maior lixiviação ocorreu na fase avançada. Esse resultado pode estar relacionado ao grau de esclerofilia das folhas, o qual diminui com a evolução do gradiente sucessional da vegetação. 
Boeger (2000), realizando estudo na mesma área, observou que na fase inicial as folhas são mais coriáceas e espessas, apresentando maior abundância de tecido esclerenquimático e menor área foliar. Já na fase avançada, as folhas apresentam-se mais finas, com maior área foliar, menor incidência de espécies com camada subepidérmica, esclerênquima e textura coriácea. Essas características das folhas, juntamente com as condições ambientais locais do sítio, que favorecem a decomposição do material vegetal, podem ter facilitado a maior liberação de nutrientes na fase avançada. Outro fator importante a ser considerado é a deposição de compostos de Ca oriundos da atmosfera (maresia, poeiras, etc.), sobre o material foliar, conforme já constatado em outros trabalhos (MARQUES; RANGER, 1997). Na fase avançada, o maior porte das árvores favoreceria a captura desse elemento da atmosfera.

\section{Magnésio}

O comportamento da lixiviação de $\mathrm{Mg}$ foi semelhante ao observado para Ca nas frações F e RFF, nas três fases sucessionais, ou seja, as quantidades aumentaram bastante do outono para o inverno, sofrendo uma queda acentuada na primavera e voltando a aumentar um pouco no verão (Figura 3).
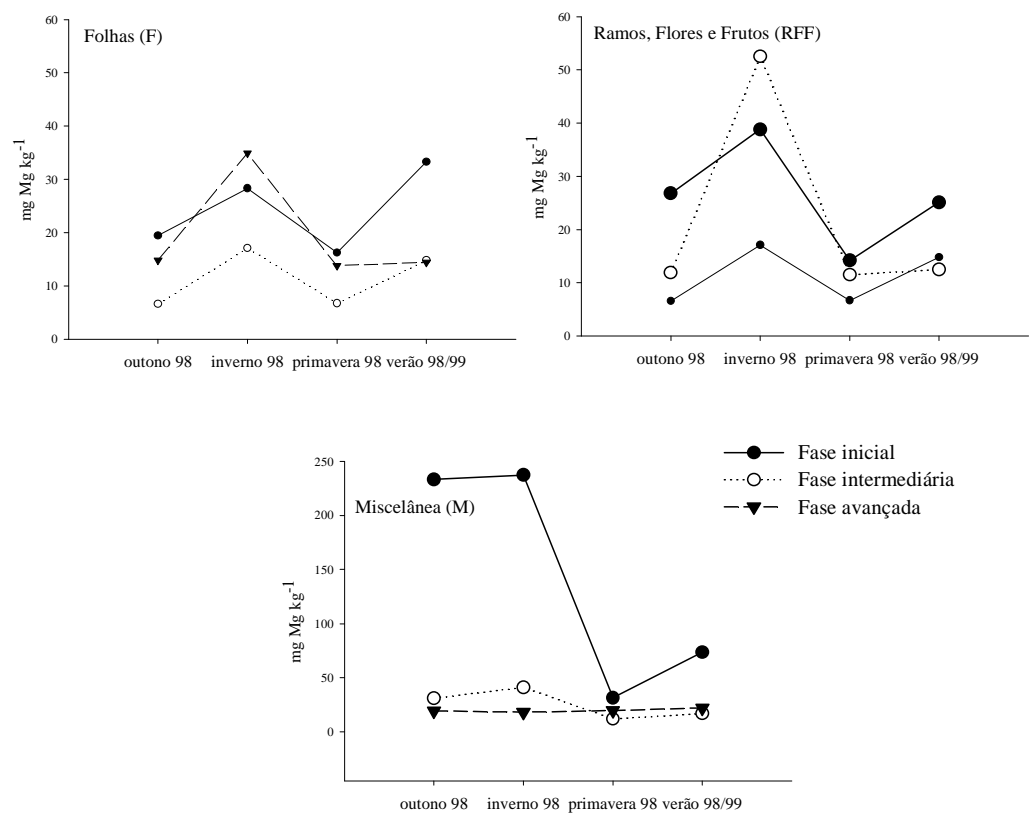

Figura 3. Quantidade estimada de $\mathrm{Mg}\left(\mathrm{mg}_{\mathrm{kg}}{ }^{-1}\right)$ no lixiviado das frações F, RFF e $\mathrm{M}$ nas fases sucessionais inicial, intermediária e avançada, ao longo das estações do ano.

Figure 3. Estimated amount of $\mathrm{Mg}\left(\mathrm{mg}_{\mathrm{kg}}{ }^{-1}\right)$ leached from the $\mathrm{F}, \mathrm{RFF}$ and $\mathrm{M}$ fractions in the initial, intermediary and advanced secondary successional stages, through the seasons of the year.

$\mathrm{Na}$ fração $\mathrm{M}$, os resultados foram bem distintos dos observados para as frações $\mathrm{F}$ e RFF. Na fase inicial ocorreu uma elevada lixiviação de $\mathrm{Mg}$ dos materiais coletados no outono e no inverno (233 e 237 mg. $\mathrm{kg}^{-1}$, respectivamente), diminuindo $86 \%$ na primavera $\left(32 \mathrm{mg} \cdot \mathrm{kg}^{-1}\right)$. Nas outras duas fases, as variações foram pequenas ao longo das estações do ano. Nessa fração, o comportamento do elemento ficou mais próximo daquele observado para o potássio.

Sódio

Nas três frações e para as três fases sucessionais, a tendência observada foi semelhante: a lixiviação do $\mathrm{Na}$ foi maior no material coletado no outono, diminuindo no inverno e mantendo-se praticamente constante na primavera e no verão (Figura 4). O sódio teria sua principal fonte na maresia que chega à floresta, próxima ao mar. Segundo Pereira (1978), as florestas de regiões costeiras recebem quantidades apreciáveis de $\mathrm{Na}, \mathrm{Cl}$ e outros nutrientes, e a entrada de nutrientes pela deposição úmida e seca apresenta variação local e temporal, de acordo com a proximidade de fontes emissoras e em relação 
à época do ano. Dessa forma, a serapilheira coletada nos meses de maior precipitação (primavera e verão) teria menos sódio aderido, para ser lixiviado durante o ensaio em casa de vegetação.
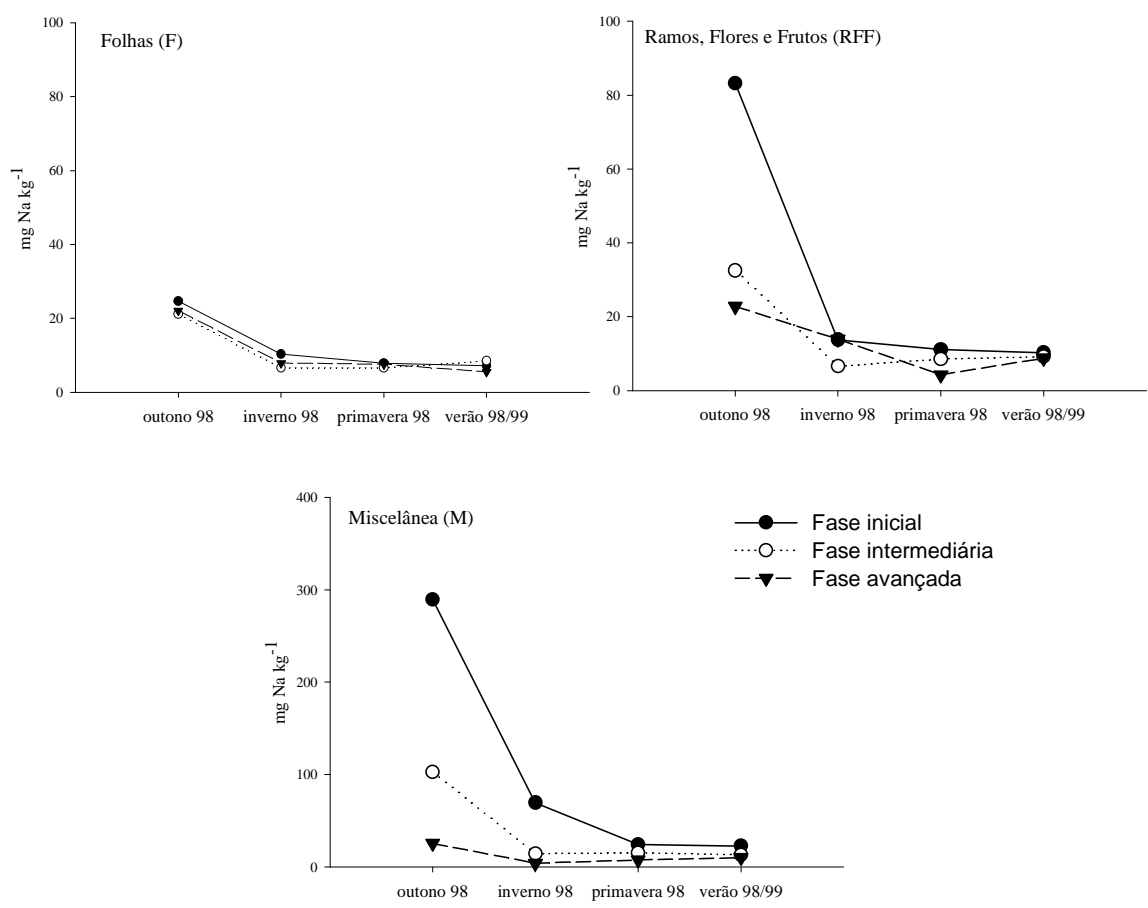

Figura 4. Quantidade estimada de $\mathrm{Na}\left(\mathrm{mg}^{\mathrm{kg}} \mathrm{kg}^{-1}\right)$ no lixiviado das frações F, RFF e M nas fases sucessionais inicial, intermediária e avançada, ao longo das estações do ano.

Figure 4. Estimated amount of $\mathrm{Na}\left(\mathrm{mg} \cdot \mathrm{kg}^{-1}\right)$ leached from the $\mathrm{F}$, RFF and $\mathrm{M}$ fractions in the initial, intermediary and advanced secondary successional stages, along the seasons of the year.

$\mathrm{Na}$ fração F, a quantidade média estimada de Na no lixiviado foi de $22 \mathrm{mg} \cdot \mathrm{kg}^{-1}$ no outono, caindo para aproximadamente $8 \mathrm{mg} \cdot \mathrm{kg}^{-1}$ no inverno. Nas frações RFF e M (fase inicial, outono), os valores encontrados foram superiores, chegando a 83 e $289 \mathrm{mg} \cdot \mathrm{kg}^{-1}$, respectivamente.

\section{Quantidades estimada e relativa de $\mathrm{K}$, Ca, Mg e Na no lixiviado das folhas de serapilheira das espécies selecionadas}

A espécie Ilex theezans (fases inicial e intermediária) foi a que mais contribuiu na liberação de nutrientes via lixiviação, antes da sua decomposição no solo, devido à sua elevada produção anual de serapilheira (acima de 3 ton.ha ${ }^{-1}$ ) (Tabela 2). Essa maior produção de serapilheira está relacionada ao fato da I. theezans ser uma espécie pioneira, com elevado valor de importância, contribuindo dessa forma com uma maior quantidade de serapilheira produzida em relação às demais espécies. Entretanto, considerandose somente as quantidades estimadas no lixiviado (do ensaio de $15 \mathrm{~mm}$ ) e não as quantidades relativas no lixiviado (considerando-se a quantidade de serapilheira produzida), essa espécie não foi a que mais liberou nutrientes. Esse comportamento pode ser devido às características morfológicas das folhas, que, segundo Boeger (2000), apresentam maior espessura total, maior espessura do parênquima paliçádico, elevada ocorrência de esclerênquima e elevada relação C/N. Essas características das folhas contribuem para tolerar as condições adversas do ambiente, como a elevada incidência da radiação solar. Outro aspecto que deve ser considerado é o estado de decomposição das folhas. Comparativamente às outras espécies estudadas, as folhas de $I$. theezans são as que menos sofreram os processos químicos e físicos da decomposição. Por esse fato, é provável que a chuva, ao entrar em contato com o material, tenha carreado menos elementos do que se as folhas estivessem mais fragmentadas e atacadas pelos organismos decompositores. A espécie Pera glabrata apresentou comportamento oposto, ou seja, a quantidade estimada dos elementos no lixiviado foi mais elevada em relação a I. theezans e às outras espécies 
(principalmente para $\mathrm{K}$ e $\mathrm{Ca}$ ), porém as quantidades relativas no lixiviado foram bem menores. Isso ocorreu devido ao menor valor de importância da espécie (Tabela 1) e, consequentemente, a uma menor deposição de serapilheira em comparação ao que foi depositado por I. theezans. A espécie Rapanea venosa apresentou as maiores quantidades estimadas de elementos no lixiviado em relação às demais espécies estudadas na fase intermediária. Em termos de quantidade relativa no lixiviado, os valores foram os mais elevados depois de I. theezans. Os resultados encontrados para as demais espécies estudadas na fase intermediária apresentaram pouca variação entre si, tanto para as quantidades estimadas quanto para as quantidades relativas no lixiviado da serapilheira.

Tabela 2. Deposição anual $\left(\mathrm{kg} \cdot \mathrm{ha}^{-1}\right)$ de serapilheira, quantidade estimada no lixiviado $\left(\mathrm{g} \cdot \mathrm{kg}^{-1}\right)$ e quantidade relativa no lixiviado $\left(\mathrm{g} \cdot \mathrm{ha}^{-1}\right.$ ) de $\mathrm{K}, \mathrm{Ca}, \mathrm{Mg}$ e $\mathrm{Na}$ das folhas de serapilheira das espécies selecionadas nas fases sucessionais inicial, intermediária e avançada, antes de sua decomposição no solo.

Table 2. Annual litter production $\left(\mathrm{kg} \cdot \mathrm{ha}^{-1}\right)$, estimated amount leached $\left(\mathrm{g} \cdot \mathrm{kg}^{-1}\right)$ and relative amount leached $\left(\mathrm{g}^{-\mathrm{ha}^{-1}}\right)$ of $\mathrm{K}, \mathrm{Ca}, \mathrm{Mg}$ and $\mathrm{Na}$ from leaf litter of the selected tree species in the initial, intermediary and advanced regeneration phases, before its decomposition in soil.

\begin{tabular}{|c|c|c|c|c|c|c|c|c|c|}
\hline \multirow[t]{2}{*}{ Fase/Espécie } & \multirow{2}{*}{ 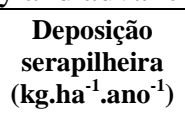 } & \multicolumn{4}{|c|}{$\begin{array}{c}\text { Quantidade estimada no lixiviado } \\
\left({\mathrm{g} . \mathrm{kg}^{-1} \text {.ano }}^{-1}\right)\end{array}$} & \multicolumn{4}{|c|}{$\begin{array}{l}\text { Quantidade relativa no lixiviado } \\
\left(\text { g.ha }^{-1} \cdot \text { ano }^{-1}\right)\end{array}$} \\
\hline & & $\mathbf{K}$ & $\mathrm{Ca}$ & Mg & $\mathbf{N a}$ & $\mathbf{K}$ & Ca & Mg & $\mathrm{Na}$ \\
\hline \multicolumn{10}{|c|}{ Inicial } \\
\hline Ilex theezans & 3394 & $0,07 \mathrm{a}^{*}$ & $0,05 \mathrm{a}$ & $0,08 \mathrm{a}$ & $0,04 \mathrm{a}$ & $63,1 \mathrm{c}$ & $35,3 \mathrm{a}$ & $78,2 \mathrm{c}$ & $26,6 \mathrm{~b}$ \\
\hline $\begin{array}{l}\text { Ternstroemia } \\
\text { brasiliensis }\end{array}$ & 335 & $0,17 \mathrm{~b}$ & $0,18 \mathrm{~b}$ & $0,22 b$ & $0,16 \mathrm{a}$ & $13,8 \mathrm{~b}$ & $11,9 \mathrm{a}$ & $15,0 \mathrm{~b}$ & $9,2 \mathrm{ab}$ \\
\hline Pera glabrata & 163 & $0,30 \mathrm{c}$ & $2,05 \mathrm{c}$ & $0,26 \mathrm{~b}$ & $0,11 \mathrm{a}$ & $13,9 \mathrm{~b}$ & $48,0 \mathrm{a}$ & $9,4 \mathrm{a}$ & $4,0 \mathrm{a}$ \\
\hline Ocotea pulchella & 94 & $0,42 \mathrm{~d}$ & $0,32 \mathrm{~b}$ & $0,37 \mathrm{c}$ & $0,17 \mathrm{a}$ & $9,2 \mathrm{a}$ & $5,7 \mathrm{a}$ & $10,6 \mathrm{a}$ & $2,8 \mathrm{a}$ \\
\hline Média & & 0,24 & 0,65 & 0,23 & 0,12 & 25,0 & 25,2 & 28,3 & 10,6 \\
\hline \multicolumn{10}{|c|}{ Intermediária } \\
\hline Ilex theezans & 2190 & $0,11 \mathrm{a}$ & $0,05 \mathrm{a}$ & $0,05 \mathrm{a}$ & $0,05 \mathrm{a}$ & $75,5 \mathrm{~d}$ & $23,7 \mathrm{~d}$ & $32,8 \mathrm{~d}$ & $22,3 \mathrm{c}$ \\
\hline Rapanea venosa & 446 & $0,27 \mathrm{~d}$ & $0,13 \mathrm{c}$ & $0,18 \mathrm{c}$ & $0,10 \mathrm{c}$ & $31,9 \mathrm{c}$ & $14,2 \mathrm{c}$ & $18,7 \mathrm{c}$ & $10,7 \mathrm{~b}$ \\
\hline Clusia criuva & 327 & $0,19 \mathrm{bc}$ & $0,14 \mathrm{c}$ & $0,11 \mathrm{~b}$ & $0,08 \mathrm{bc}$ & $16,8 \mathrm{a}$ & $10,7 \mathrm{ab}$ & $8,8 \mathrm{a}$ & $5,7 \mathrm{a}$ \\
\hline $\begin{array}{l}\text { Ternstroemia } \\
\text { brasiliensis }\end{array}$ & 459 & $0,19 \mathrm{bc}$ & $0,09 \mathrm{~b}$ & $0,13 b$ & $0,07 \mathrm{ab}$ & $26,9 \mathrm{bc}$ & $8,5 \mathrm{a}$ & $14,6 \mathrm{bc}$ & $6,9 \mathrm{a}$ \\
\hline $\begin{array}{l}\text { Gomidesia } \\
\text { schaueriana }\end{array}$ & 300 & $0,23 \mathrm{~cd}$ & $0,15 \mathrm{c}$ & $0,13 b$ & $0,09 \mathrm{bc}$ & $18,2 \mathrm{a}$ & $11,2 \mathrm{ab}$ & $9,6 \mathrm{a}$ & $5,6 \mathrm{a}$ \\
\hline Ocotea pulchella & 378 & $0,16 \mathrm{ab}$ & $0,13 \mathrm{c}$ & $0,10 \mathrm{~b}$ & $0,05 \mathrm{a}$ & $19,9 \mathrm{ab}$ & $13,4 \mathrm{c}$ & $12,7 \mathrm{ab}$ & $5,4 \mathrm{a}$ \\
\hline Média & & 0,19 & 0,12 & 0,12 & 0,07 & 31,5 & 13,6 & 16,2 & 9,4 \\
\hline \multicolumn{10}{|c|}{ Avançada } \\
\hline Tapirira guianensis & 1067 & $0,24 \mathrm{a}$ & $0,13 \mathrm{a}$ & $0,14 \mathrm{a}$ & $0,05 \mathrm{a}$ & $70,0 \mathrm{c}$ & $35,1 \mathrm{~b}$ & $27,1 \mathrm{ab}$ & $7,7 \mathrm{c}$ \\
\hline Ocotea aciphylla & 757 & $0,26 \mathrm{a}$ & $0,12 \mathrm{a}$ & $0,15 \mathrm{a}$ & $0,04 \mathrm{a}$ & $42,0 \mathrm{~b}$ & $16,2 \mathrm{a}$ & $34,1 \mathrm{~b}$ & $6,3 \mathrm{~b}$ \\
\hline Ocotea pulchella & 355 & $0,31 \mathrm{a}$ & $0,14 \mathrm{a}$ & $0,21 \mathrm{a}$ & $0,04 \mathrm{a}$ & $28,8 \mathrm{a}$ & $13,6 \mathrm{a}$ & $28,7 \mathrm{ab}$ & $4,1 \mathrm{a}$ \\
\hline Myrcia racemosa & 156 & $1,50 \mathrm{~b}$ & $0,73 \mathrm{~b}$ & $0,62 \mathrm{~b}$ & $0,16 \mathrm{~b}$ & $57,5 \mathrm{c}$ & $20,2 \mathrm{a}$ & $22,6 \mathrm{a}$ & $4,6 \mathrm{a}$ \\
\hline Média & & 0,58 & 0,28 & 0,28 & 0,07 & 49,6 & 21,3 & 28,1 & 5,7 \\
\hline
\end{tabular}

* Valores em colunas seguidos de mesma letra não diferem entre si pelo teste de Fischer's protected LSD, ao nível de 5\%.

Na fase avançada, a espécie Myrcia racemosa apresentou as maiores quantidades estimadas dos elementos no lixiviado, porém as maiores quantidades relativas dos elementos no lixiviado foram observadas para a espécie Tapirira guianensis. Isso ocorreu porque essa espécie produziu quase 7 vezes mais serapilheira que $M$. racemosa. Nas fases intermediária e avançada, a ordem decrescente das quantidades estimadas médias dos elementos no lixiviado foi a seguinte: $\mathrm{K}>\mathrm{Ca}=\mathrm{Mg}>\mathrm{Na}$. Esses resultados estão de acordo com os encontrados na literatura. Golley et al. (1978), em estudo realizado em floresta tropical úmida, observaram que a concentração mineral do lixiviado do dossel da floresta foi dominada por K, Ca e Na. Berhard-Reversat, citado por Marschner (1986), trabalhando também em florestas tropicais úmidas, observou que o acúmulo dos elementos minerais lixiviados do dossel expressam quantidades de magnitude elevada, apresentando a seguinte ordem: $\mathrm{K}>\mathrm{N}>\mathrm{Mg}>\mathrm{Ca}>\mathrm{P}$. 
Na fase inicial, houve uma inversão entre Ca e K na ordem de lixiviação. Esta maior lixiviação de Ca observada na fase inicial ocorreu devido à influência da espécie P. glabrata, a qual apresentou quantidade estimada de Ca no lixiviado muito superior às demais espécies (2,05 g. $\mathrm{kg}^{-1}$ ano-1 $)$ (Tabela 2).

A maior quantidade estimada média de $\mathrm{K}$ no lixiviado ocorreu na fase avançada da sucessão. É provável que essa maior lixiviação seja devida a características morfológicas das folhas da serapilheira (menor esclerofilia) e a características do sítio, as quais estariam proporcionando maior decomposição do material vegetal e, portanto, maior liberação de nutrientes, como é o caso do K. Peña (2002), estudando o mesmo ecossistema, observou que na fase avançada existe uma maior atividade microbiana, a qual se justificou por características microclimáticas do sítio resultantes de maior espessura e umidade dos horizontes orgânicos, maior teor de matéria orgânica e menor temperatura. A elevada produção de $\mathrm{CO}_{2}$, ou seja, elevada respiração microbiana, indicou maior atividade de micro-organismos em relação às outras fases sucessionais.

O comportamento do Na foi oposto ao do K, ou seja, a maior quantidade estimada média de $\mathrm{K}$ no lixiviado ocorreu na fase inicial em relação às fases intermediária e avançada. Isso está, em parte, relacionado com os teores foliares de $\mathrm{Na}$, que tendem a ser superiores nas espécies da fase sucessional inicial (PINTO e MARQUES, 2003). As maiores contribuições em termos de quantidade relativa dos elementos no lixiviado foram das seguintes espécies: I. theezans (fases inicial e intermediária), $R$. venosa (fase intermediária) e T. guianensis (fase avançada).

\section{Porcentagem de lixiviação de $\mathrm{K}$, Ca, Mg e Na das folhas de serapilheira das espécies selecionadas}

A relação percentual entre a quantidade de nutrientes depositada via serapilheira e a quantidade relativa dos elementos no lixiviado dessa mesma serapilheira foi avaliada para as folhas das espécies selecionadas nas três fases sucessionais (Tabela 3 ).

Tabela 3. Quantidade depositada $\left(\mathrm{kg}_{\mathrm{h}} \mathrm{ha}^{-1} \cdot \mathrm{ano}^{-1}\right)$, quantidade relativa no lixiviado e porcentagem de lixiviação de $\mathrm{K}, \mathrm{Ca}, \mathrm{Mg}$ e $\mathrm{Na}$ das folhas de serapilheira das espécies selecionadas nas fases sucessionais inicial, intermediária e avançada, antes de sua decomposição no solo.

Table 3. Amount of $\mathrm{K}, \mathrm{Ca}, \mathrm{Mg}$ and $\mathrm{Na}$ in litterfall, leached and percentage of leaching from selected tree species leaves in the initial, intermediary and advanced regeneration phases, before its decomposition in soil.

\begin{tabular}{|c|c|c|c|c|c|c|c|c|c|c|c|c|}
\hline \multirow[t]{2}{*}{ Fase/Espécie } & \multicolumn{4}{|c|}{$\begin{array}{c}\text { Quantidade depositada } \\
\left(\text { kg.ha }^{-1} \cdot \text { ano }^{-1}\right)\end{array}$} & \multicolumn{4}{|c|}{ 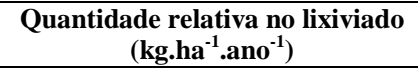 } & \multicolumn{4}{|c|}{$\begin{array}{c}\text { Lixiviação } \\
(\%)\end{array}$} \\
\hline & $\mathbf{K}$ & $\mathbf{C a}$ & Mg & $\mathrm{Na}$ & $\mathbf{K}$ & $\mathbf{C a}$ & $\mathrm{Mg}$ & $\mathrm{Na}$ & $\mathbf{K}$ & $\mathbf{C a}$ & Mg & $\mathrm{Na}$ \\
\hline \multicolumn{13}{|c|}{ Inicial } \\
\hline Ilex theezans & 3,16 & 39,71 & 18,22 & 0,56 & 63,15 & 35,31 & 78,21 & 26,68 & 2,0 & 0,1 & 0,4 & 4,8 \\
\hline $\begin{array}{l}\text { Ternstroemia } \\
\text { brasiliensis }\end{array}$ & 0,34 & 3,69 & 1,21 & 0,04 & 13,82 & 12,17 & 15,04 & 4,67 & 4,1 & 0,3 & 1,2 & 12,9 \\
\hline Pera glabrata & 0,35 & 3,64 & 1,34 & 0,03 & 19,36 & 9,72 & 17,33 & 5,92 & 5,5 & 0,3 & 1,3 & 17,8 \\
\hline Média & 1,3 & 15,7 & 6,9 & 0,2 & 32,1 & 19,1 & 36,9 & 12,4 & 3,9 & 0,2 & 1,0 & 11,8 \\
\hline \multicolumn{13}{|c|}{ Intermediária } \\
\hline Ilex theezans & 3,58 & 17,19 & 8,78 & 0,43 & 75,43 & 23,72 & 32,89 & 22,29 & 2,1 & 0,1 & 0,4 & 5,2 \\
\hline Rapanea venosa & 0,55 & 4,44 & 1,15 & 0,06 & 26,21 & 11,40 & 13,76 & 7,85 & 4,7 & 0,3 & 1,2 & 13,4 \\
\hline Clusia criuva & 0,55 & 4,38 & 1,06 & 0,04 & 15,91 & 10,67 & 8,47 & 4,13 & 2,9 & 0,2 & 0,8 & 10,8 \\
\hline $\begin{array}{l}\text { Ternstroemia } \\
\text { brasiliensis }\end{array}$ & 0,76 & 3,74 & 2,04 & 0,06 & 30,14 & 10,29 & 17,70 & 8,41 & 4,0 & 0,3 & 0,9 & 13,2 \\
\hline $\begin{array}{l}\text { Gomidesia } \\
\text { schaueriana }\end{array}$ & 0,49 & 1,86 & 0,75 & 0,03 & 18,23 & 11,20 & 9,60 & 5,59 & 3,8 & 0,6 & 1,3 & 17,2 \\
\hline Ocotea pulchella & 0,43 & 2,42 & 0,67 & 0,02 & 20,24 & 13,37 & 13,02 & 6,06 & 4,7 & 0,6 & 2,0 & 24,6 \\
\hline Média & 1,1 & 5,7 & 2,4 & 0,1 & 31,0 & 13,4 & 15,9 & 9,1 & 3,7 & 0,3 & 1,1 & 14,1 \\
\hline \multicolumn{13}{|c|}{ Avançada } \\
\hline $\begin{array}{l}\text { Tapirira } \\
\text { guianensis }\end{array}$ & 2,04 & 14,44 & 2,54 & 0,05 & 70,92 & 34,51 & 19,61 & 6,98 & 3,5 & 0,2 & 0,8 & 14,4 \\
\hline Ocotea aciphylla & 1,21 & 5,57 & 1,56 & 0,04 & 40,98 & 14,96 & 14,62 & 6,17 & 3,4 & 0,3 & 0,9 & 17,0 \\
\hline Ocotea pulchella & 0,42 & 2,40 & 0,65 & 0,02 & 29,01 & 12,22 & 9,73 & 4,47 & 6,9 & 0,5 & 1,5 & 23,9 \\
\hline Myrcia racemosa & 0,30 & 2,54 & 0,50 & 0,01 & 56,66 & 17,57 & 14,58 & 4,50 & 18,8 & 0,7 & 2,9 & 59,7 \\
\hline Média & 1,0 & 6,2 & 1,3 & 0,03 & 49,4 & 19,8 & 14,6 & 5,5 & 8,1 & 0,4 & 1,5 & 28,7 \\
\hline
\end{tabular}


Para todas as espécies estudadas, independentemente da fase sucessional, a porcentagem de lixiviação apresentou a seguinte ordem decrescente: $\mathrm{Na}>\mathrm{K}>\mathrm{Mg}>\mathrm{Ca}$. O Na, por ser um elemento caracteristicamente de origem atmosférica (EATON et al., 1973), foi o elemento mais lixiviado das folhas da serapilheira. Isso ocorreu devido à proximidade da área de estudo com o mar (apenas $17 \mathrm{~km}$ ), favorecendo a deposição de sais de sódio, principalmente de $\mathrm{NaCl}$, sobre a vegetação do local. $\mathrm{O} \mathrm{K}$ foi o segundo elemento mais lixiviado. A origem desse elemento também pode ser via deposição atmosférica, porém é mais provável que tenha sido oriundo do próprio tecido vegetal após interação com a água deionizada.

A maior porcentagem média de lixiviação do $\mathrm{K}$ foi observada na fase avançada. As porcentagens médias de lixiviação de $\mathrm{Ca}$ e $\mathrm{Mg}$ aumentaram um pouco da fase inicial para a fase avançada, e a do Na foi quase 3 vezes maior na fase avançada em relação à fase inicial. Essa tendência de haver maior lixiviação nas folhas de serapilheira das fases sucessionais avançadas pode estar relacionada às características morfológicas das folhas, que, conforme Boeger (2005), apresentam-se mais finas e com maior valor médio de área foliar. As folhas, por apresentarem maior área foliar, tenderiam a acumular maiores quantidades de bioelementos. Além disso, a textura mais fina e lisa favoreceria a liberação de elementos químicos das folhas, seja por lixiviação ou pela lavagem dos elementos depositados superficialmente (PROTIL, 2006).

As espécies que apresentaram as maiores porcentagens de lixiviação dos quatro elementos analisados foram P. glabrata (fase inicial), O. pulchella (fase intermediária) e M. racemosa (fase avançada). Boeger e Wisniewski (2003) realizaram um estudo comparativo da morfologia foliar de espécies arbóreas na mesma área deste trabalho e observaram que a espécie $O$. pulchella apresentou a menor área foliar $\left(4,5 \mathrm{~cm}^{2}\right)$, a menor espessura total $(240 \mu \mathrm{m})$ e as epidermes das faces abaxial e adaxial mais finas (12,3 e $8,4 \mu \mathrm{m}$, respectivamente), comparativamente às outras espécies avaliadas na fase intermediária. Na fase avançada, $M$. racemosa apresentou as folhas mais finas $(128 \mu \mathrm{m})$, cutícula da face adaxial mais fina $(2,3 \mu \mathrm{m})$ e epidermes das faces abaxial e adaxial mais finas $(11,7$ e $8,4 \mu \mathrm{m}$, respectivamente), comparativamente às outras espécies avaliadas nessa fase. Essas características morfológicas, somadas a fatores bióticos e abióticos do meio, devem ter favorecido o processo de decomposição foliar e, consequentemente, a liberação de nutrientes de seus tecidos (exceto para o $\mathrm{Na}$, cuja origem principal é a deposição atmosférica).

\section{CONCLUSÕES}

A variação na liberação de nutrientes pela lixiviação, observada na serapilheira coletada ao longo das estações do ano, sugere grande influência das condições climáticas na sua composição química.

A diferença observada entre as frações, com relação à liberação de nutrientes da serapilheira antes de sua decomposição no solo, está relacionada com aspectos físicos e químicos dessas frações. A menor liberação de nutrientes no lixiviado da fração folhas, relativamente à fração miscelânea (na qual o material vegetal está mais decomposto), indica que grande parte dos nutrientes só será liberada pela degradação do material vegetal.

As espécies com maior valor de importância foram as que apresentaram maior produção de serapilheira e, consequentemente, foram as que mais contribuíram na liberação de nutrientes através do processo de lixiviação.

O aumento na liberação de nutrientes, através da lixiviação, à medida que a sucessão vegetal evolui, esteve relacionado às características morfológicas das folhas e às condições de sítio favoráveis a uma maior decomposição do material vegetal na fase avançada.

$\mathrm{O}$ fato de as espécies terem se comportado de maneira diferenciada com relação à ciclagem dos nutrientes é de relevante importância ecológica, pois garante a manutenção de um equilíbrio biogeoquímico no ecossistema.

Por outro lado, o conhecimento desse fato é importante para subsidiar a recomendação de espécies em projetos de recuperação de áreas degradadas. Espécies que apresentam elevada produção de serapilheira e que, adicionalmente, reciclam grande quantidade de nutrientes são espécies-chave para acelerar os processos de recuperação das áreas.

\section{REFERÊNCIAS}

BOEGER, M. R. T.; WISNIEWSKI, C.; REISSMANN, C. B. Nutrientes foliares de espécies arbóreas de três estádios sucessionais de Floresta Ombrófila Densa no sul do Brasil. Acta Botânica Brasílica, Porto alegre, v. 19, n. 1, p. 167-181, 2005. 
BOEGER, M. R. T.; WISNIEWSKI, C. Comparação da morfologia foliar de espécies arbóreas de três estádios sucessionais distintos de Floresta Ombrófila Densa (Floresta Atlântica) no sul do Brasil. Revista Brasileira de Botânica, São Paulo, v. 26, n. 1, p. 61-72, 2003.

BOEGER, M. R. T. Morfologia foliar e aspectos nutricionais de espécies arbóreas em três estádios sucessionais, de Floresta Ombrófila Densa das Terras Baixas, Paranaguá, PR.. 150 f. Tese (Doutorado em Ciências Florestais) - Setor de Ciências Agrárias, Universidade Federal do Paraná, Curitiba, 2000.

BRITEZ, R. M. Ciclagem de nutrientes minerais em duas florestas da planície litorânea da Ilha do Mel, Paranaguá, PR. 240 f. Dissertação (Mestrado em Engenharia Florestal) - Setor de Ciências Agrárias, Universidade Federal do Paraná, Curitiba, 1994.

EATON, S. J.; LIKENS, G. E. E.; BORMANN, F. H. Throughfall and stemflow chemistry in a Northern hardwood forest. The Journal of Ecology, Oxford, v. 61, n. 2, p. 495-508, 1973.

GOLLEY, F. B.; McGINNIS, J. T.; CLEMENTS, R. G.; CHILD, G. I.; DUEVER, M. J. Ciclagem de minerais em um ecossistema de Floresta Tropical Úmida. São Paulo: E. P. U. EDUSP, 1978.

GÓMEZ-POMPA, A.; VÁSQUEZ-YANES, C. Sucessional studies of a rainforest in Mexico. In: WEST, D. C.; SCHUGART, H. H.; BOTKIN, D. B. Forest Sucession: concepts and application. New York: Spring-Verlag, 1981. p. 246-266.

INSTITUTO AGRONÔMICO DO PARANÁ (IAPAR). Cartas climáticas básicas do Estado do Paraná. Londrina, 1978, 41 p.

JONES JUNIOR., J. B. Plant nutrition. Florida: CRC Press LLC, 1998. 149 p.

MALAVOLTA, E. Elementos de nutrição mineral de plantas. São Paulo: Agronômica Ceres, 1980.

MARQUES, R.; RANGER, J. Nutrient dynamics in a chronosequence of Douglas-fir (Pseudotsuga menziesii (Mirb.) Franco) stands on the Beaujolais Mounts (France). 1: Qualitative approach. Forest Ecology and Management, Amsterdam, v. 91, p. 255-277, 1997.

MARSCHNER, H. Mineral nutrition of higher plants. London: Academic, 1986.

MENGEL, K.; KIRKBY, E. A. Principles of plant nutrition. Berna: International Postash Institute, 1987.

PEÑA PEÑA, M. L. Indicadores microbiológicos de solo na avaliação da recuperação de área degradada de Floresta Ombrófila Densa das Terras Baixas no Litoral Paranaense - Brasil. $71 \mathrm{f}$. Dissertação (Mestrado em Ciência do Solo) - Setor de Ciências Agrárias, Universidade Federal do Paraná, Curitiba, 2002.

PINTO, C. B.; MARQUES, R. Aporte de nutrientes por frações da serapilheira em sucessão ecológica de um ecossistema da floresta atlântica. Floresta, Curitiba, v. 33, n. 3, p. 257-264, 2003.

PROTIL. C. Z. Contribuição de quatro espécies arbóreas ao ciclo biogeoquímico em Floresta Atlântica na planície litorânea do Paraná. 128 f. Tese (Doutorado em Engenharia Florestal) - Setor de Ciências Agrárias, Universidade Federal do Paraná, Curitiba, 2006.

SOUZA, L. C. Dinâmica de nutrientes na precipitação, em solução de solo e lençol freático em três tipologias florestais sobre Espodossolo, no Litoral do Paraná. 89 f. Tese (Doutorado em Ciências Florestais) - Setor de Ciências Agrárias, Universidade Federal do Paraná., Curitiba, 2006.

SPURR, S. H.; BARNES, B. V. Forest Ecology. 3. ed. New York: John Wiley, 1980. 670 p.

WISNIEWSKI, C. (Coord.). Caracterização do ecossistema e estudo das relações solo - cobertura vegetal em planície pleistocênica do litoral paranaense. Curitiba, 1997, 55 p. Projeto Integrado CNPq. 